\title{
COVID-19 and Geriatric Mental Health: the biopsychosocial aspects
}

\author{
Avinash De Sousa ${ }^{1}$, Karishma Rupani $^{2}$ \\ ${ }^{1}$ Consultant Psychiatrist and Founder Trustee, Desousa Foundation, Mumbai. \\ ${ }^{2}$ Assistant Professor, Department of Psychiatry, Seth G.S. Medical College and K.E.M. Hospital, Mumbai. \\ Corresponding author - Avinash De Sousa \\ E-mail-avinashdes888@gmail.com
}

There is already a plethora of research done on COVID-19 and the mental health of the general population. However, there are many factors that make the effect of COVID-19 on geriatric mental health different from that on the general population. The COVID-19 pandemic world over has been unprecedented. With limited means for treatment, the mainstay of public health intervention has been social isolation, so as to prevent contagion. Let us understand some biopsychosocial issues specific to the elderly. Older people are vulnerable to severe viral infection [1] as they often have associated comorbidities [2]. Studies show that with advancing age, the severity and the mortality of the population increases [3]. To add to this, elderly people have a higher prevalence of cognitive impairment and due to this cognitive vulnerability [4], they find it difficult to keep up with the huge amount of information on COVID-19 and to implement preventive measures meticulously. Among them, those with neurodegenerative disorders, especially dementia have a greater risk of death as a consequence of COVID infection [5]. Therefore, the very notion of vulnerability, presence of comorbidities and other factors can be significant stressors and precipitate psychological distress in this population. However not all people in the geriatric population pool have a heightened risk of infection or death. Thus, there must be certain other specific factors accounting for the increased morbidity and mortality.

Frailty is a factor specific to the geriatric population. Frailty is an age-related multidimensional clinical condition defined as 'a non-specific state of vulnerability, identifying older people at increased risk of falls, institutionalization, hospitalization, disability, dementia, and death'. It has been defined as 'a dynamic state affecting an elderly individual who experiences injuries in one or more human function fields (physical, psychological, social), that increases the risk of adverse health outcomes' [6]. Basic physical need fulfilment is required to experience physical well-being and hence physical frailty is considered as a lack of resources to fulfil one's basic physical needs. In the same vein, social frailty is considered as a lack of resources to fulfil one's basic social needs [7]. Fulfilment of basic social needs is necessary to function adequately and experience social well-being, that is, just as basic physical need fulfilment is required to experience physical well-being, social need fulfilment is required for social well-being. Studies have shown greater incidence of neuropsychiatric disorders, directly proportional to the social frailty status, as late consequences during the times of the earlier pandemics [8-9]. During the COVID-19 pandemic as well, early death cases occurred primarily in older people with a social frailty status, possibly due to a weaker immune system fostering faster progression of the viral infection [10]. Hence, a correct assessment of social frailty is needed to prevent late life neuropsychiatric disorders precipitated by the COVID19 pandemic.

For a certain section of the geriatric population, sadly physical distancing has resulted in social distancing as most older people tend to socialize at community centres and religious temples [11]. However, due to the containment strategies these places have become inaccessible, something that generates feelings of social and psychological isolation in this age group, especially in those without access to or the technical know-how of using social platforms. This has increased the risk of depression and anxiety in the elderly [12]. The visits to the elderly in nursing homes have been restricted or even banned, making interaction 
with family members more difficult and exacerbating feelings of isolation [13], which can worsen mental health [14]. Similarly, sadness and hopelessness have been reported in isolated elderly with dementia [15].

Violence against older people, who are already bearing the brunt of this pandemic, has risen sharply since the beginning of the COVID-19 pandemic and imposition of lockdown measures not only in their homes, but also in the old age homes. Considering them vulnerable, they are very often left to fend for themselves, with few resources to continue their consultation with the doctors for existing chronic physical ailments, in person. This amounts to neglect [16]. All in all, the situation surrounding COVID-19 (e.g., stress, health care access and social distancing) is likely to exacerbate pre-existing health conditions as well as health disparities among older adults, which may contribute to late-life suicide [17]. There has also been a rise in elderly suicides reported during the COVID-19 pandemic. COVID-19 prevention and treatment measures have fuelled experiences of social isolation, perceived expendability, and exposure to suffering, which are related to the 3 main components of the interpersonal theory of suicide (i.e., thwarted belongingness, perceived burdensomeness to society and capability for suicide). Also, the pandemic has been a trigger for the recurrence of previous psychiatric disorders, as they limit therapeutic adherence and amplify negative emotions.

Studies have reported a steep worsening of neuropsychiatric symptoms (NPS), including depression, anxiety, anger, agitation, insomnia in the elderly during the pandemic [18]. Findings from the study by Helms and colleagues suggested that the most common neurological features in the elderly COVID19 patients were non-focal: confusion, agitation, dysexecutive syndrome, and diffusely brisk reflexes [19]. Worsening of cognitive impairment in elderly patients with dementia has been reported during the few months following the beginning of the pandemic [20]. Apathy is of special interest as it is known to be exacerbated by acute medical conditions. Medical conditions cause cognitive impairment which in turn tends to increase apathy [21] making it a vicious circle that can be broken if interventions are specially designed for this subset of the population. Findings show that COVID-19 has been associated with a 25\% increase in the incidence of psychotic outbreak cases In the elderly, there has also been an increase in the risk of schizophrenia, as the mean age for patients newly diagnosed with schizophrenia changed from 39 to 50 years [22].

The elderly with pre-existing dementia and cognitive impairment have limited access to accurate information and facts about the pandemic [23]. Also, they may not correctly follow recommendations to reduce the spread of COVID-19 (such as hygiene and precautionary measures), because they cannot remember procedures or understand important information [23]. Social distancing effects are also reflected in people with dementia due to withdrawal of certain non-pharmacological treatment modalities of dementia. Possible trauma resulting from these changes can further accelerate cognitive decline.

In case of co-occurrence of COVID-19 and dementia, delirium could complicate the presentation of dementia [24]. Loss of interpersonal monitoring may increase the risk of dehydration, infections, and the decompensation of chronic diseases, such as diabetes or hypertension [25]. Similarly impairments in the interpretation and outward expression of stimuli in their internal milieu related to medical conditions, such as pain, confusion, headache may be expressed via aberrant arousal and motor responses, i.e., anxiety and agitation [26].

A systematic review and meta-analysis on recovered patients of other coronaviruses found that a significant proportion of patients developed delirium during the acute stage, and almost half (44\%) had memory impairment post-illness. In patients with dementia, delirium could complicate the presentation of dementia. As a result of neuro-inflammation that causes and progresses neurodegenerative processes in the brain, it is suggested that COVID-19 could result in a higher incidence of neurodegenerative diseases [27].

COVID-19 has multiple routes to enter the CNS. One is directly through the cribriform plate and olfactory bulb, the other through the hematogenous route, wherein the virus crosses the blood brain barrier and via the Gut Associated Myeloid lymphoid tissue (MALT). SARS COV-2 is neurotropic, attaches to the ACE (Angiotensin Converting Enzyme) receptor of the neuronal cell and replicates within the cell ultimately leading to neuronal cell death. This presents clinically as impaired cognitive functioning (e.g. memory impairment or attention problems), confusion, headache or encephalitis, encephalopathy and stroke (as a 
result of thrombotic complication, inflammatory consequences, hypoxia, blood pressure dysregulation [27]. As a result of inflammatory processes, C-reactive protein, ferritin, and interleukin-6 levels were found to be high in patients with covid-19. Thus, some of the psychiatric co-morbidities can be explained by the well-established and documented interplay between inflammation and both depression and psychosis [2830]. The downstream effects of loneliness on neural networks and systemic health is mediated by stressrelated and inflammatory processes. It has been seen that loneliness is linked to elevated cardiovascular and neuroendocrine markers of stress, impaired sleep, and proinflammatory physiological effects, that can cause neurodegeneration in the hippocampus and in other brain regions delegated to emotional regulation and cognition [31]. Together, these processes may lead some older individuals to cope less efficiently with COVID-19 pandemic stressors and may increase emotional dysregulation, leading to an increased risk for late-life suicide [32]. Quantitatively, increase in loneliness was associated with greater brain amyloid- $\beta$ (A $\beta$ ) protein burden. These associations were stronger in apolipoprotein E $\varepsilon 4$ allele carriers [33]. Epigenomic studies investigated molecular mechanisms by which loneliness exacerbates a wide range of neurodegenerative, psychiatric, and somatic diseases [34]. Home-isolation also tends to affect vitamin D levels by reducing the number of hours spent outdoors. There is evidence that vitamin D deficiency is linked to impaired immune function, potentially causing autoimmunity and increased risk of infections [35]. Recent studies have shown that psychosocial interventions (cognitive behaviour therapy and multiple or combined interventions) are linked to an enhanced immune system function (with decrease in proinflammatory cytokines or markers) and may therefore be useful for improving immune related health [37-38].

Studies indicate an association between higher levels of total physical activity and reduced symptoms of depression in older adults as physical activity is beneficial for both the mental and physical health of older adults, and recent recommendations have called for programs to help increase physical activity and exercise indoors to ameliorate the negative psychological and physical consequences of the COVID-19 quarantine. Clinicians should be vigilant for CNS involvement and possible neurological manifestations of COVID-19. As we have learnt, the post-COVID-19 neuropsychiatric symptoms are not uncommon and hence a diligent follow is necessary, with due importance to cognitive screening and assessment of those recovering from cognitive deficits, stroke, encephalopathy. This should not only be conducted in hospitalized COVID-19 patients, but also in the OPD setting. For those on antihypertensive medication, it is now established that they can be continued safely in those who are already on them and for those in which day would be indicated as per evidence to this day [39]. Telecommunication can step up to be user friendly. One must keep a high index of suspicion regarding elder abuse. Provide information about local services (e.g. helplines, counselling services, adult protective services) for victims of violence against older people. The biopsychosocial model of frailty could add important advantages in terms of both assessment and intervention targets.

\section{What we all must do}

Housing societies need to start helping senior citizens in their campuses and make sure that they are safe and look after their daily needs. Their movement out of the house must be reduced and any help that can be offered to them in the form of daily needs, food and medical care must be provided. Many of the elders may have some teething issues when it comes to technology, video calling and banking in the digital format. We, the younger generation can help them learn the same and even assist them in the same and help them stay in touch with their families.

Many elders may undergo bouts of sadness and anxiety and they may brood over issues like death, the end of the world, next life as well as whether this pandemic is the end of their lives. It is at such times that we have to maintain extreme patience and listen to them. Someone talking to them and allaying their primitive fears is all that they need and this would add a silver lining to their cloud. The most important feeling that elders yearn for is to feel secure and if our societies can provide the same, many of them will fight fit and overcome this current situation.

Healthcare personnel also need to be sensitive to the needs of the elderly and must be patient with them if they arrive for a check-up suspecting that they may have contracted the dreaded coronavirus. The doctor with a soothing touch and reassuring words would help them quell their anxiety with regard to illness and 
death. It is important for healthcare systems to understand that most elders hate hospitals and they must be quarantined and managed at home if possible, to help them feel protected and safe.

The COVID-19 pandemic is far from over. We are preparing for the days ahead and the elders in our societies, buildings, communities and cities need our care. The world and India have a huge population that is graying. It is left to us to color those shades of grey and create a beautiful hue for the future. Start each day, with a grateful heart.

\section{REFERENCES}

1. Girdhar R, Srivastava V, Sethi S. Managing mental health issues among elderly during COVID-19 pandemic. J Geriatr Care Res 2020;7:29-32.

2. Apidechkul T. Prevalence and factors associated with type 2 diabetes mellitus and hypertension among the hill tribe elderly populations in northern Thailand. BMC Pub. Health 2018;694.

3. Abbatecola AM, Antonelli-Incalzi R. Editorial: COVID-19 spiraling of frailty in older italian patients. J Nutr Health Aging 2020;24(5):453-5.

4. Fontes WHA, Gonsalves Junior J, de Vasconcelos CAC, da Silva CGL and Gadelha MSV. Impacts of the SARS-CoV-2 Pandemic on theMental Health of the Elderly. Front. Psychiatry 2020;11:841.

5. Covino M, De Matteis G, Santoro M, Sabia L, Simeoni B, Candelli M, et al. Clinical characteristics and prognostic factors in COVID-19 patients aged $\geq 80$ years. Geriatr Gerontol Int 2020;20(7):704-8.

6. Solfrizzi V, Scafato E, Lozupone M, Seripa D, Schilardi A, Custodero C, et al. Biopsychosocial frailty and the risk of incident dementia: the Italian longitudinal study on aging. Alzheim Dementia 2019;15:1019-28.

7. Bunt S, Steverink N, Olthof J, van der Schans CP, Hobbelen JSM. Social frailty in older adults: a scoping review. Eur J Ageing 2017; 14:32334.

8. Tsutsumimoto K, Doi T, Makizako H, Hotta R, Nakakubo S, Makino K, et al. Association of social frailty with both cognitive and physical deficits among older people. J Am Med Dir Assoc 2017;18:603-7.

9. Tsutsumimoto K, Doi T, Makizako H, Hotta R, Nakakubo S, Kim M, et al. Social frailty has a stronger impact on the onset of depressive symptoms than physical frailty or cognitive impairment: a 4-year follow-up longitudinal cohort study. J Am Med Dir Assoc. 2018;19:504-10.

10. Lozupone M, La Montagna M, DiGioia I, Sardone R, Resta E, Daniele A, Giannelli G, Bellomo A and Panza F. Social Frailty in the COVID-19 Pandemic Era. Front. Psychiatry 2020;11:577113.

11. Reynolds K, Pietrzak RH, El-Gabalawy R, Mackenzie CS, Sareen J. Prevalence of psychiatric disorders in U.S. older adults: Findings from a nationally representative survey. World Psychiaty 2015;14:74-81.

12. Armitage R, Nellums LB. COVID-19 and the consequences of isolating the elderly. Lancet Pub. Health 2020;5:e256.

13. Wang D, Hu B, Hu C, Zhu F, Liu X, Zhang J, et al. Clinical characteristics of 138 hospitalized patients with 2019 novel coronavirus-infected pneumonia in Wuhan, China. JAMA 2020;323(11):1061-9.

14. Sanders R. COVID-19, social isolation and loneliness. Iris. April 22,2020.

15. Edelman LS, McConnell ES, Kennerly SM, Alderden J, Horn SD, Yap TL. Mitigating the effects of a pandemic: facilitating improved nursing home care delivery through technology. JMIR Aging 2020;3(1):e20110.

16. Storey JE. Risk factors for elder abuse and neglect: A review of the literature. Aggress Viol Behaviour 2020; 50:1-13.

17. Dorn AV, Cooney RE, Sabin ML. COVID-19 exacerbating inequalities in the US. Lancet 2020; 395(10232);1243-4.

18. Bianchetti A, Rozzini R, Guerini F, Boffelli S, Ranieri P, Minelli G, et al. Clinical presentation of COVID19 in dementia patients. J Nutr Health Aging 2020;24(6):560-2.

19. Helms J, Kremer S, Merdji H, Clere-Jehl R, Schenck M, Kummerlen C, et al. Neurologic features in severe SARS-CoV-2 infection. N Engl J Med 2020;382:2268-70.

20. Lara B, Carnes A, Dakterzada F, Benitez I, Piñol-Ripoll G. Neuropsychiatric symptoms and quality of life in Spanish patients with Alzheimer's disease during the COVID-19 lockdown. Eur J Neurol 2020;27:1744-7.

21. Bunn F, Burn AM, Goodman C, Rait G, Norton S, Robinson L, et al. Comorbidity and dementia: a scoping review of the literature. BMC Med 2014;12:192.

22. Brown E, Kumar S, Rajji TK, Pollock BG, Mulsant BH. Anticipating and mitigating the impact of the COVID-19 pandemic on Alzheimer's disease and related dementias. Am J Geriatr Psychiatry 2020;28(7):712-21.

23. Wang H, Li T, Barbarino P, Gauthier S, Brodaty H, Molinuevo JL, et al. Dementia care during COVID-19. Lancet 2020;395(10231):1190-1.

24. Brown E, Kumar S, Rajji TK, Pollock BG, Mulsant BH. Anticipating and mitigating the impact of the COVID-19 pandemic on Alzheimer's disease and related dementias. Am J Geriatr Psychiatry 2020;28(7):712-21.

25. Brodaty $\mathrm{H}$, Arasaratnam C. Meta-analysis of nonpharmacological interventions for neuropsychiatric symptoms of dementia. Am J Psychiatry 2012;169(9):946-53. 
26. Trzepacz PT, Yu P, Bhamidipati PK, Willis B, Forrester T, Tabas L, et al. Frontolimbic atrophy is associated with agitation and aggression in mild cognitive impairment and Alzheimer's disease. Alzheim Dement 2013;9(5 Suppl):S95-104.

27. Wenting A, Gruters A, van Os Y, Verstraeten S, Valentijn S, Ponds R and de Vugt M. COVID-19 Neurological Manifestations and Underlying Mechanisms: A Scoping Review. Front Psychiatry 2020;11:860.

28. Mehta P, McAuley DF, Brown M, Sanchez E, Tattersall RS, Manson JJ. COVID-19: consider cytokine storm syndromes and immunosuppression. Lancet 2020;395:1033-4.

29. Wohleb ES, Franklin T, Iwata M, Duman RS. Integrating neuroimmune systems in the neurobiology of depression. Nat Rev Neurosci 2016;17:497-511.

30. Ferrando SJ, Klepacz L, Lynch S, Tavakkoli M, Dornbush R, Baharani R, et al. COVID-19 Psychosis: a potential new neuropsychiatric condition triggered by novel coronavirus infection and the inflammatory response? Psychosomatics 2020 (Ahead of print).

31. Hawkley LC, Cacioppo JT. Loneliness matters: a theoretical and empirical review of consequences and mechanisms. Ann Behav Med 2010;40:218-27.

32. Lupien SJ, McEwen BS, Gunnar MR, Heim C. Effects of stress throughout the lifespan on the brain, behaviour and cognition. Nat Rev Neurosci 2019;10(6):434-45.

33. Rosenberg PB. Loneliness as a marker of brain amyloid burden and preclinical Alzheimer disease. JAMA Psychiatry 2016;73:1237-8.

34. Canli T, Yu L, Yu X, Zhao H, Fleischman D, Wilson RS, et al. Loneliness 5 years ante-mortem is associated with disease-related differential gene expression in postmortem dorsolateral prefrontal cortex. Transl Psychiatry 2018;8:2.

35. Vanherwegen AS, Gysemans C, Mathieu C. Regulation of immune function by vitamin D and its use in diseases of immunity. Endocrinol Metab Clin N Am 2017;46:1061-94.

36. Meems LM, de Borst MH, Postma DS, Vonk JM, Kremer HPH, Schuttelaar M-LA, et al. Low levels of vitamin $\mathrm{D}$ are associated with multimorbidity: results from the Lifelines Cohort Study. Ann Med 2015;47:474- 81 .

37. Slavich GM, Auerbach RP. Stress and its sequelae: depression, suicide, inflammation, and physical illness. In: Butcher JN, Hooley JM, editors. APA Handbook of Psychopathology: Psychopathology: Understanding, Assessing, and Treating Adult Mental Disorders, Vol 1. Washington, DC: American Psychological Association ;2018: New York. Pp.375-402.

38. Slavich GM. Psychoneuroimmunology of stress and mental health. In: Harkness KL, Hayden EP, editors. The Oxford Handbook of Stress and Mental Health. New York, NY: Oxford University Press 2020; UK. p. 519-46.

39. Kai H, Kai M. Interactions of coronaviruses with ACE2, angiotensin II, and RAS inhibitors-lessons from available evidence and insights into COVID-19. Hypertens Res 2020;43:648-54.

$$
\begin{aligned}
& \text { Acknowledgements - Nil } \\
& \text { Source of Funding - Nil } \\
& \text { Conflict of Interest - Nil }
\end{aligned}
$$

